\title{
INTEGRAÇÃO INTRA E INTERORGANIZACIONAL NO DESENVOLVIMENTO DE PRODUTOS: ESTUDO DE CASO NO SETOR DE LATICÍNIOS
}

\section{INTRA AND INTER-ORGANIZATIONAL INTEGRATION IN THE DEVELOPMENT OF NEW PRODUCTS: CASE STUDY OF DAIRY'S COMPANY}

\author{
Silvia Satiko Onoyama ${ }^{1}$; Marcia Mitiko Onoyama ${ }^{2}$ José Edson Lara ${ }^{3}$; Maria Rita Pontes Assumpção ${ }^{4}$ José \\ Carlos de Toledo ${ }^{5}$ \\ ${ }^{1}$ Empresa Brasileira de Pesquisa Agropecuária - EMBRAPA - Brasília - Brasil \\ silonoyama@yahoo.com \\ ${ }^{2}$ Federal University of São Carlos - UFSCAR - São Carlos - Brasil \\ onoyama@dep.ufscar.br \\ ${ }^{3}$ Federal University of Minas Gerais - UFMG - Belo Horizonte - Brasil \\ jedson@,face.ufmg.br \\ ${ }^{4}$ SENAI- Centro Integrado de Manufatura e Tecnologia- SENAI CIMATEC - Salvador - Brasil \\ mariarpa@cimatec.fieb.org.br \\ ${ }^{5}$ Federal University of São Carlos - UFSCAR - São Carlos - Brasil \\ toledo@dep.ufscar.br
}

\begin{abstract}
Resumo
O exercício da inovação em produtos reveste-se de ampla complexidade, causando dependência entre as áreas da organização, pois requerem inputs e cooperação entre os agentes de diversos departamentos funcionais, como Marketing, Produção, Pesquisa e Desenvolvimento e Garantia da Qualidade, além de buscar incorporar a capacitação tecnológica dos fornecedores no processo de desenvolvimento de produtos. Este trabalho analisa as integrações intra e interorganizacional no desenvolvimento de produtos lácteos. Este setor tem dirigido seus esforços em prol da reestruturação tecnológica e organizacional, buscando implementar inovações que viabilizem a rapidez e a qualidade do desenvolvimento de produtos e a melhoria da gestão e deste processo. Optou-se por realizar uma pesquisa exploratória, com uso do método qualitativo de estudo de caso, em uma empresa de laticínios e um de seus fornecedores de ingredientes. Os resultados obtidos mostram que, mesmo desenvolvendo produtos já existentes no mercado, observa-se uma integração entre as áreas funcionais e uma parceria com os fornecedores no processo de desenvolvimento de produtos da empresa. No entanto, não há uma reflexão sobre os papéis de cada departamento funcional, e do fornecedor para o sucesso ou fracasso do projeto. Verificou-se, também, que a extensão da participação do fornecedor no desenvolvimento de produto está relacionado à diferença na competência técnica entre a empresa cliente e o fornecedor.
\end{abstract}

Palavras-chave: desenvolvimento de produtos, integração, novos produtos 


\section{Introdução}

O sucesso de uma organização de manufatura está intimamente associado à sua capacidade de introduzir novos produtos no mercado que satisfaçam as necessidades dos clientes. $\mathrm{O}$ desenvolvimento de produtos constitui vantagem competitiva para uma empresa quanto maior for seu diferencial com relação aos concorrentes no que diz respeito a atendimento das necessidades do consumidor, qualidade e preço. Para isso, são necessários investimentos na dinamização e no encurtamento dos prazos de desenvolvimento e de lançamento de produtos no mercado (SOBRAL, 2002).

Entretanto, o processo de desenvolvimento de produtos reveste-se de ampla complexidade, que engloba as necessidades voláteis dos consumidores, o avanço da tecnologia e o dinamismo da legislação, dentre outros (SONG et al., 1998). Essas incertezas causam dependência entre as áreas da organização, pois requerem inputs e cooperação entre os agentes dos diversos departamentos funcionais, como Marketing, Produção, Pesquisa e Desenvolvimento (P\&D) e Qualidade, no intuito de alcançar a congruência da gestão da inovação.

Clark e Fujimoto (1991), Clark e Wheelwright (1993) e Rozenfeld et al. (2006) também apontam a integração com fontes externas, tais como os fornecedores, para compartilhar informações de natureza econômica e tecnológica no intuito de otimizar o processo. Fleury e Fleury (2003) consideram a competência de fornecedores como forma de contribuição para a diferenciação do produto, na visão de que a eficiência é buscada coletivamente em redes inter-organizacionais e não apenas individualmente (empresa isolada).

À luz desse cenário, muitos estudos abordaram separadamente as relações intra e interorganizacionais e poucos se aventuraram numa análise entre as cooperações internas e externas. Com a finalidade de diminuir esta diferença, Hillebrand e Biemans (2004) propuseram que a integração multifuncional potencializa a cooperação externa. Outrossim, a articulação entre as áreas funcionais da empresa e fornecedores favorece a reunião de conhecimentos diversos no intuito de maximizar os projetos de desenvolvimento de produtos, pois a concepção e o projeto detalhado do produto devem advir de fontes e de forma integradas, englobando os fornecedores e a obtenção das vozes dos clientes e das áreas de manufatura.

O objetivo deste trabalho é realizar uma pesquisa exploratória com o intuito de analisar as integrações intra e interorganizacional no desenvolvimento de produtos lácteos, focando as iniciativas para compartilhamento de ações no desenvolvimento de novos produtos. $\mathrm{O}$ reconhecimento da importância do setor alimentício encontra eco em autores como Toledo et al. (2005), que o apontam como destaque no âmbito nacional. No contínuo processo de atender ao forte embate competitivo globalizado, o setor tem dirigido seus esforços em prol da reestruturação 
tecnológica e organizacional, buscando implementar inovações que viabilizem a rapidez do desenvolvimento de produtos e a melhoria do processo e da gestão de desenvolvimento de produtos. Complementando, Martinelli Jr.(1999) e Onoyama (2006) observam que a indústria de alimentos é fortemente dependente das inovações e do progresso técnico desenvolvidos em outros setores industriais, destacando-se as indústrias química e farmacêutica, com novas soluções para os ingredientes; e o setor de bens de capital (máquinas, equipamentos), na engenharia de processo.

Para Castro e Neves (2001), um dos segmentos de alimentos que tem aumentado sua representatividade no âmbito nacional é o de laticínios, já que a partir dos anos noventa ocorreram grandes transformações em toda a cadeia agroindustrial do leite, devido à desregulamentação do mercado, a abertura e estabilização da economia. Essas mudanças potencializaram a modernização das estruturas de produção e de comercialização, ancoradas no desenvolvimento de novos produtos.

\section{Referencial Teórico}

O referencial teórico adotado atende duas perspectivas: gestão de desenvolvimento de produtos e integração intra e interfuncional.

\subsection{Gestão do Processo de Desenvolvimento de Produto (PDP)}

O processo de desenvolvimento de novos produtos prioriza as necessidades do mercado, com objetivo de lançar um produto que atenda aos atributos relativos à qualidade, com desenvolvimento no tempo adequado e a um custo de projeto compatível. Além disso, precisa assegurar a manufaturabilidade (processabilidade) do produto desenvolvido, atendendo às restrições de custo e qualidade. No entendimento de Clark e Fujimoto (1991), o modo como a empresa realiza o desenvolvimento de produtos, nos âmbitos da velocidade, eficiência e qualidade do processo, irá definir a competitividade do produto.

Sendo assim, o desenvolvimento de produtos deve abranger todo o planejamento e gerenciamento do portfólio de produtos (que estão: no mercado, sendo lançados e em fase de desenvolvimento) e do portfólio de projetos (em fase de planejamento, em andamento e concluídos), garantindo compatibilidade com as estratégias da empresa. É necessário abranger, também, a especificação de todos os recursos e procedimentos de manufatura, envolvendo aquisição de máquinas, equipamentos, ferramentas e, quando necessário, a construção de novas unidades de produção. Isto é, envolve tanto a gestão estratégica (alinhamento estratégico dos projetos de desenvolvimento com a estratégia do negócio, maximização do valor do portfólio de projetos levando em consideração os recursos disponíveis e balanceamento entre projetos sob diversos critérios) quanto a gestão operacional (para sistematizar as interações entre as fases do PDP e as 
pessoas e empresas envolvidas) desse processo de negócio, considerando aspectos de mercado e da manufatura (ROZENFELD et al., 2006).

De acordo com Griffin (1997) e Cheng (2000), as empresas com as melhores práticas de P\&D utilizam um processo formal como guia da gestão operacional do desenvolvimento de produtos. O processo formal de desenvolvimento apresenta diversas variações, assumindo formas diferentes de organização a organização, mas os princípios permanecem os mesmos, já que todos abordam geração da idéia, elaboração do conceito do produto, desenvolvimento do produto e do processo e lançamento do produto. Neste sentido, as empresas têm a possibilidade de seguir modelos puros da literatura, modelos adaptados e até mesmos modelos próprios.

$\mathrm{Na}$ indústria de alimentos, por exemplo, o modelo de Fuller é bastante difundido, devido à especificidade de sua elaboração para este setor. Este modelo estabelece seis etapas para o desenvolvimento de produtos alimentícios: concepção de idéias, conceituação, desenvolvimento, produção, avaliação pelos consumidores e teste de mercado (FULLER,1994).

Para Toledo et al. (2006), o uso de boas práticas de gestão nas atividades inerentes ao PDP, atento aos aspectos estratégicos e a boa coordenação interna e externa facilitam alcançar melhores resultados em termos de eficiência e eficácia do desempenho do PDP da empresa.

\subsection{Integração intra e interorganizacional}

\subsubsection{Integração intraorganizacional}

No intuito de obter sucesso no lançamento de produtos, faz-se necessário estimular a integração entre os diversos setores da empresa para o processo de desenvolvimento de novos produtos . A integração é definida, neste contexto, como compartilhamento de informações e envolvimento entre as funções nas ações do processo de desenvolvimento de produtos (GUPTA et al., 1986; SONG et al., 1998; OLSON et al., 2001).

Um trabalho conjunto entre os setores de Marketing, Pesquisa e Desenvolvimento, Produção, Finanças e outros favorece a reunião de conhecimentos diversos para maximizar o projeto de $\mathrm{P} \& \mathrm{D}$, pois a concepção e o produto não devem advir de fontes separadas, mas de fonte de integração, englobando desde a área de Engenharia até a obtenção da voz do cliente (CLARK; WHEELWRIGHT, 1993). Kahn (2001) reconhece a importância da integração entre os diversos setores da empresa no processo de desenvolvimento de produtos, por favorecer o aumento da flexibilidade frente às mudanças inesperadas durante o desenvolvimento, como também a visão do projeto como um todo e não fragmentado em partes.

Em que pese seus benefícios, a integração intraorganizacional em desenvolvimento de produtos, ou outros processos organizacionais, defronta-se com barreiras geradoras de conflito que 
debilitam a conexão e a cooperação entre as funções. Para Griffin e Hauser (1996), personalidades diversificadas, diferentes modos de ver o fenômeno, linguagem, responsabilidades organizacionais e barreiras físicas, entre outros, respondem pela formação de barreiras e conflitos no processo de inovação. Por isso, alertam os autores, os mecanismos de coordenação para integração dos atores são necessários no processo de inovação. Segundo os mesmos autores, as empresas têm utilizado seis abordagens para integrar os departamentos funcionais: realocação e projeto dos recursos físicos; rotatividade de profissionais; sistemas sociais informais; estrutura organizacional; incentivos e prêmios; e processos formais integrativos gerenciais.

Alguns modelos extraídos da literatura sobre integração entre as esferas da organização compõem a base de sustento deste trabalho. Resgatando o modelo de Gupta et al.(1986) expõe-se a integração (Figura 1) entre os departamentos de Marketing e de Pesquisa e Desenvolvimento, considerando o nível de cooperação dependente da estratégia de desenvolvimento da empresa, na perspectiva de Miles e Snow (1978): prospectora, analisadora, defensora ou reatora; além das incertezas do ambiente externo. Entretanto, o grau de integração atingido advém dos fatores organizacionais, tais como a sua estrutura da equipe multidisciplinar e o apoio da alta gerência. Além dos fatores organizacionais, os fatores individuais que enquadram as diferenças sócioculturais entre os gerentes dos departamentos, também influenciam no grau de integração alcançada.

A partir dos fatores organizacionais e individuais, se delineia o nível de integração entre os departamentos. A diferença entre o ideal, que é a integração necessária, e o real, forma o gap de integração. Se a diferença entre a necessidade de integração desejada pela organização e a efetivada for grande, o sucesso do desenvolvimento de novos produtos pode ser comprometido, pois o nível de integração alcançado não é o suficiente para responder às demandas externas. Se o lapso for pequeno, significa que houve a integração desejada pela organização, e esta poderá afetar positivamente o processo de novos produtos. O sucesso de novos produtos é fortemente ancorado pelos indicadores de desempenho do produto, envolvendo as esferas mercadológicas, financeiras e técnicas (GRIFFIN; HAUSER, 1996).

Por fim, estudos mais recentes têm tratado a integração multifuncional em nível operacional, focalizando as relações entre os departamentos em cada estágio do processo de desenvolvimento (SONG et al., 1998). Estes autores destacam que cada estágio pode afetar a natureza e a força da relação entre as áreas funcionais e o desempenho do projeto, pois a complexidade do ambiente e a turbulência interferem em cada etapa do processo de desenvolvimento de maneira diferente. 
Figura 1 - Modelo da integração entre Marketing e P\&D

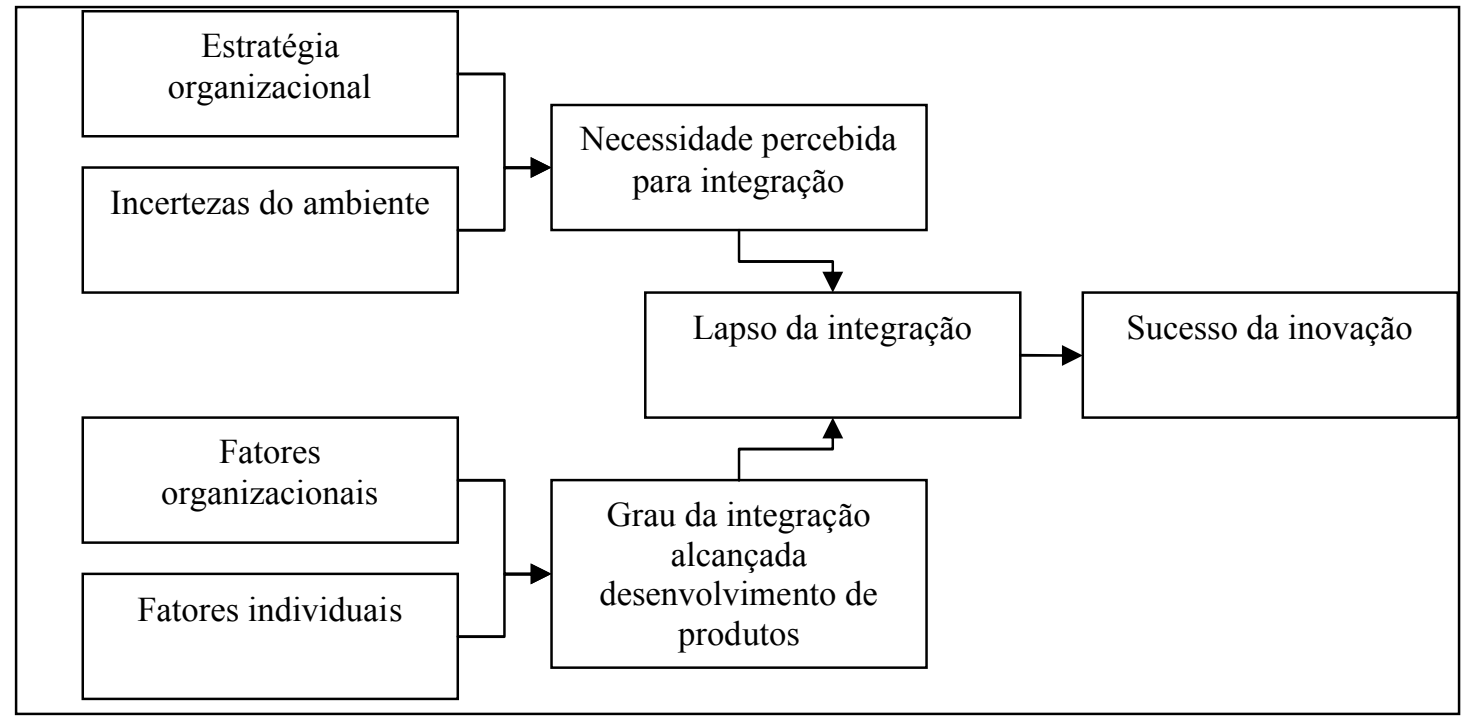

Fonte: GUPTA et al (1986)

Ampliando o escopo do desenvolvimento de novos produtos, as empresas têm opção de se associarem a fornecedores, detentores de tecnologia ou expertise, para trabalharem em conjunto, devido ao know-how solicitado para determinados projetos (SOBRAL, 2003). Ragatz et. al (1997) e Handfield et. al (1999) também verificaram que o relacionamento colaborativo com os fornecedores no desenvolvimento de novos produtos tem como resultado: redução de custos e melhoria na qualidade dos materiais adquiridos, redução no tempo de desenvolvimento de produtos e maior facilidade de acesso e aplicação de tecnologia.

\subsubsection{Integração interorganizacional}

O grau de interação entre fornecedor e cliente industrial depende do tamanho, do objetivo e da complexidade do projeto, assim como do grau de intensidade tecnológica incorporada ao bem fornecido (AMARAL, 1997). A Figura 2 apresenta os pontos possíveis de interação do fornecedor no processo de desenvolvimento de produto.

Figura 2 - Interação dos Fornecedores no Processo de Desenvolvimento do Produto

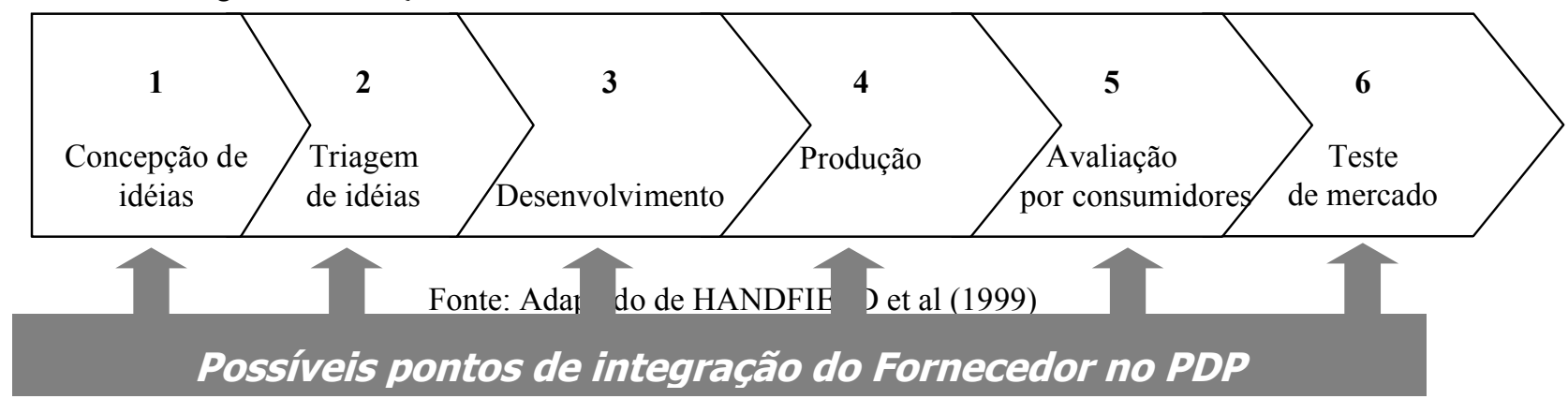


O envolvimento dos fornecedores no PDP pode ser amplo, desde a participação no projeto da embalagem, até a proposição de nova formulação do produto final, levando a diferentes tipos de envolvimento de fornecedores no PDP. Segundo Hood et. al (1995), os fornecedores de ingredientes para a indústria de alimentos podem atuar no desenvolvimento de novos produtos para seus clientes segundo várias formas como indica o Quadro 1, caracterizando diferentes tipos de fornecedores.

Quadro 1 - Tipos de Assistência Técnica do fornecedor para o cliente industrial

\begin{tabular}{|c|c|c|c|c|c|c|}
\hline \multicolumn{7}{|c|}{ Processo de Desenvolvimento do Produto (PDP) - Fuller (1994) } \\
\hline \multirow{10}{*}{ 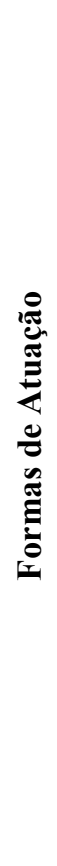 } & $\begin{array}{l}\text { 1.Concepção de } \\
\text { idéias }\end{array}$ & $\begin{array}{l}\text { 2.Triagem } \\
\text { de idéias }\end{array}$ & 3.Desenvolvimento & 4.Produção & $\begin{array}{l}\text { 5.Avaliação } \\
\text { por } \\
\text { Consumidores }\end{array}$ & $\begin{array}{l}\text { 6.Teste de } \\
\text { Mercado }\end{array}$ \\
\hline & Geração de Idéias & $\begin{array}{l}\text { Seleção da } \\
\text { Idéia }\end{array}$ & $\begin{array}{l}\text { Formulação do } \\
\text { Produto }\end{array}$ & $\begin{array}{l}\text { Desenvolvimento } \\
\text { de Protótipos }\end{array}$ & Análise Sensorial & Comercialização \\
\hline & Avaliação de Riscos & & Teste de Viabilidade & & & Marketing \\
\hline & $\begin{array}{l}\text { Indica Novos } \\
\text { Ingredientes }\end{array}$ & & $\begin{array}{l}\text { Tempo de Validade } \\
\text { do Produto }\end{array}$ & & & \\
\hline & $\begin{array}{l}\text { Auditorias de } \\
\text { Campo }\end{array}$ & & Legislação & & & \\
\hline & & & Teste de Tolerância & & & \\
\hline & & & $\begin{array}{l}\text { Melhoria da } \\
\text { Qualidade }\end{array}$ & & & \\
\hline & & & $\begin{array}{l}\text { Design de } \\
\text { equipamentos }\end{array}$ & & & \\
\hline & & & $\begin{array}{l}\text { Melhorias de } \\
\text { processo }\end{array}$ & & & \\
\hline & & & $\begin{array}{l}\text { Engenharia de } \\
\text { Processo }\end{array}$ & & & \\
\hline
\end{tabular}

Fonte: Adaptado de HOOD et al (1995) por ONOYAMA (2006)

Esta variedade de formas de participação dos fornecedores no desenvolvimento de produtos possibilita o desenvolvimento de tipologias de envolvimento de fornecedores no PDP. Neste estudo é referendada a tipologia de projetos desenvolvida por Clark e Fujimoto (1991). Parte-se do pressuposto que, determinando-se quais os tipos de envolvimento de fornecedores e de projetos de desenvolvimento, é possível caracterizar o grau de participação do fornecedor no projeto do cliente.

Os fornecedores podem ser classificados de modos diferentes, dependendo da extensão da sua participação no desenvolvimento de produto do cliente industrial. Clark e Fujimoto (1991) apresentam uma tipologia para avaliar a participação do fornecedor no PDP. Esta tipologia para projetos junto aos fornecedores de componentes/subsistemas é proveniente de estudos na indústria automobilística. São identificados quatro tipos de projetos, de acordo com o fluxo de informações entre a montadora e os fornecedores de autopeças envolvidos no projeto. Os tipos de projeto são: peças de propriedade do fornecedor, black box, peça de controle detalhado pelo cliente (também conhecido como gray Box) e adaptação de peças de controle detalhado pelo cliente (Quadro 2). 
Quadro 2 - Tipos de projetos encontrados na indústria automobilística.

\begin{tabular}{|l|l|}
\hline Tipo de Projeto & Descrição \\
\hline Peça de propriedade do fornecedor & $\begin{array}{l}\text { Componente ou sistema padrão desenvolvido e manufaturado } \\
\text { pelo fornecedor }\end{array}$ \\
\hline "Black Box" & $\begin{array}{l}\text { O cliente estabelece as metas de desempenho, detalhes de } \\
\text { interface- forma exterior e outros aspectos básicos e o } \\
\text { fornecedor faz a engenharia detalhada. }\end{array}$ \\
\hline $\begin{array}{l}\text { Peça de controle detalhado pelo cliente } \\
\text { ou "gray box" }\end{array}$ & $\begin{array}{l}\text { Projeto do produto é do cliente e o fornecedor desenvolve o } \\
\text { processo, podendo construir ou não protótipo } \\
\text { Envolvimento tardio no PDP }\end{array}$ \\
\hline $\begin{array}{l}\text { Adaptação de Peças de Controle } \\
\text { Detalhado pelo cliente }\end{array}$ & $\begin{array}{l}\text { Idem ao anterior, mas o fornecedor pode sugerir alterações } \\
\text { ou, mesmo o cliente, pode também requisitá-las. }\end{array}$ \\
\hline
\end{tabular}

Fonte: Adaptado de CLARK e FUJIMOTO (1991) por AMARAL e TOLEDO (2000)

Neste contexto, as colaborações externas e internas otimizam o processo ao favorecer sinergia entre as partes, ao facilitar o fluxo de informação, devido à ausência de barreiras entre as áreas funcionais e entre as empresas, contribuindo, assim, para o sucesso do projeto como um todo e de seu resultado. Entretanto, a ampla literatura registra as contribuições de ambas de forma separada, não discutindo a relação entre elas para a eficácia do desenvolvimento de produtos (HILLERBRAND; BIEMANS, 2004).

Takeishi (2001) observa que a integração com os fornecedores só é possível se a organização tiver uma coordenação interna. Hillerbrand e Biemans (2004), em sua pesquisa exploratória, apontam que a integração interfuncional é um pré-requisito para um relacionamento efetivo interorganizacional, servindo como mecanismo para coordenar a cooperação externa.

Os relacionamentos externos necessitam ser bem coordenados internamente pela empresa para ter sucesso. O grau e a qualidade da cooperação interna precisam unir tanto a necessidade de cooperação interna quanto a da externa.

Amparado pelo referencial construído mediante revisão de literatura, este trabalho adotou a arquitetura de integração indicada na Figura 3.

Figura 3 - Modelo do estudo proposto

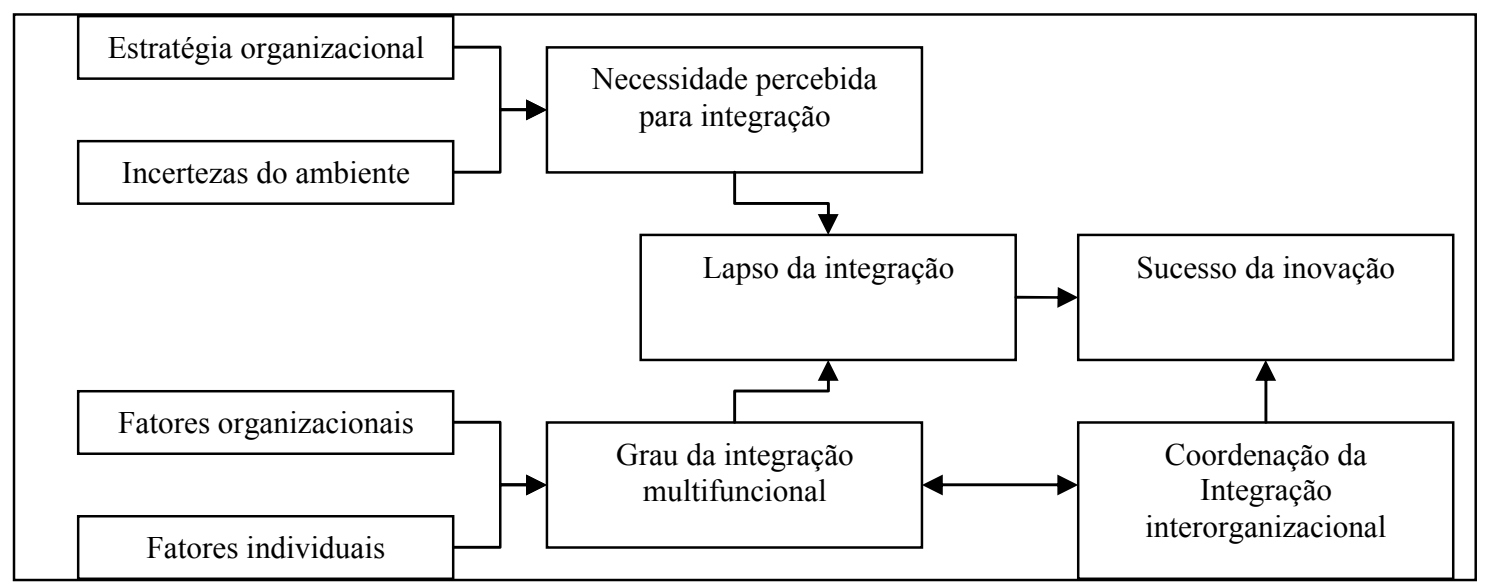

Fonte: Adaptado de GUPTA et al. (1986); SONG et al. (1998) e HANDFIELD et al (1999) 
A proposta aborda a influência dos fatores externos (legislação, consumidor, competidor e tecnologia) e da estratégia segundo a ótica de Miles e Snow (1978) na necessidade de integração entre os departamentos. Para impulsionar a cooperação, dois fatores internos foram pesquisados: os aspectos organizacionais e os individuais. Os fatores organizacionais englobam a tipologia de equipe multifuncional e a adesão da alta gerência em relação ao projeto. A análise dos fatores individuais limitou-se às causas de conflito entre os departamentos, por não ser foco deste trabalho avaliar as diferenças quanto a formação da equipe. Em seqüência, foi tratado a atuação dos atores na gestão estratégica e durante cada etapa do processo. O grau de integração da organização influencia diretamente as relações dos fornecedores com o desenvolvimento de produtos.Tanto o relacionamento do binômio ideal/real da integração organizacional quanto o envolvimento dos fornecedores impulsionam o sucesso do desenvolvimento de produtos.

\section{Metodologia}

A pesquisa realizada neste trabalho é de natureza qualitativa, conduzida por estudo de caso, cuja unidade de análise é um fornecedor de ingredientes e uma empresa de laticínios. De acordo com Vianna (2001) na pesquisa qualitativa são analisadas cada situação a partir de seus dados descritivos, buscando identificar relações, causas, efeitos, conseqüências e outros aspectos considerados necessários à compreensão da realidade estudada e que, geralmente envolve múltiplos aspectos.

A partir do objetivo desta análise e seguindo a orientação de Yin (2001), identificou-se a estratégia de estudo de caso como a mais adequada para esta pesquisa pelo tipo de questão de pesquisa proposta, da extensão de controle sobre os eventos comportamentais efetivos e do enfoque em acontecimentos contemporâneos.

Para a coleta de dados foram utilizadas informações primárias e secundárias. O uso de várias fontes de evidências nos estudos de caso permite que o pesquisador dedique-se a uma ampla diversidade de questões históricas, comportamentais e de atitudes (YIN, 2001).

A fase de levantamento dos dados secundários abrangeu ampla pesquisa bibliográfica, envolvendo jornais e periódicos especializados, documentos internos e sites das empresas estudadas, além de levantamento de pesquisas previamente realizadas.

As entrevistas semi-estruturadas foram direcionadas aos profissionais de P\&D, Marketing, Qualidade, Produção, Compras e um gestor do fornecedor, todos integrantes do processo de desenvolvimento de produtos, com o objetivo de enriquecer as informações secundárias coletadas 
em fase anterior, e descrever como ocorre a integração desses setores no processo de desenvolvimento de novos produtos (Quadro 3).

Quadro 3 - Unidades de análise

\begin{tabular}{|c|c|}
\hline Empresa & Profissionais entrevistados \\
\hline Fornecedor A & Gerente comercial \\
& Representante comercial \\
\hline Empresa Alfa & Assessor de marketing \\
& Coordenador de compras \\
& Engenheira de alimentos \\
& Controler comercial \\
& Planejamento de produção e registro do produto \\
\hline
\end{tabular}

\section{Análise de Resultados}

\subsection{Descrição das empresas}

\section{Empresa Alfa}

A empresa Alfa é uma central de cooperativas formada, atualmente, por 32 filiadas. Atua como compradora de insumos, processadora de matérias-primas e vendedora de produtos finais. Reúne 12 mil cooperados indiretos e 6 mil fornecedores não cooperados em Goiás e Minas, além de empregar 3.800 funcionários.

A sua missão reflete sua preocupação em produzir e comercializar produtos de origem láctea, garantir qualidade para os clientes e retorno satisfatório para os cooperados fornecedores de leite, acionistas e empregados, respeitando o meio ambiente. A sua visão consiste em se posicionar entre as maiores e mais competitivas indústrias de alimentos do Brasil permanecendo controlada pelo sistema cooperativista.

\section{Fornecedor A}

O fornecedor A pertence a uma empresa suíça, com matriz em Genebra. Possui 50 filiais distribuídas nos países europeus, nas Américas, Oceania e Ásia, empregando mais de 5000 funcionários. A empresa ocupa a terceira posição mundial no mercado de aromas e fragrâncias, com market share de $12 \%$ e taxa de crescimento de $8,7 \%$ ao ano. Seu faturamento em 2004 foi cerca de 2 bilhões de francos suíços. Esta empresa possui 5 unidades produtivas na América Latina: México, Colômbia, Venezuela, Argentina e Brasil. A unidade fabril brasileira localiza-se em Cotia no Estado de São Paulo, embora atenda a toda América Latina. Possui 225 funcionários, entre pessoal administrativo e de produção. 


\subsection{Integração intraorganizacional}

As incertezas do ambiente percebidas pela organização para o desenvolvimento de novos produtos geram a necessidade de integração entre os departamentos. Com relação a integração intraorganizacional, foram consideradas para análise quatro esferas do ambiente externo (modelo de Gupta et al.): legislação, consumidor, competidor e tecnologia.

- Para a empresa Alfa a legislação exerce interferência (influência) de grau entre médio e alto no desenvolvimento do produto, já que engloba o registro do produto e a composição da formulação.

- No intuito de atender ao desenvolvimento de produtos, a disponibilidade de tecnologia influencia muito.

- No entendimento dos entrevistados, as necessidades dos consumidores finais interferem muito no portfólio de novos produtos. As incertezas geradas por esta esfera fazem com que as tendências de mercado sejam captadas e estudadas, pois a empresa tem procurado, no decorrer dos anos, evitar falhas no lançamento de novos produtos, por ser muito oneroso.

- Os entrevistados mencionaram que o cenário do setor lácteo é altamente competitivo. Segundo a responsável pelo $\mathrm{P} \& \mathrm{D}$, porém "as empresas regionais não os incomodam. Preços e posicionamento dependem das multinacionais".

O controle dessas variáveis permite à empresa Alfa enfrentar, predizer e compreender as influencias do ambiente externo. Para tanto ela busca informações em pesquisa de mercado, pesquisas informais com varejistas, atacadistas e consumidores finais além de parcerias com fornecedores, que serão tratadas no próximo tópico.

As informações obtidas fazem com que as empresas reflitam seus objetivos e suas necessidades, instituindo estratégias para enfrentar o ambiente competitivo. A empresa Alfa estudada posiciona-se como analisadora, segundo a tipologia de Miles e Snow (1978), e raramente lidera a entrada no mercado com novos produtos, tendo como uma das justificativas a limitação de recursos técnicos, financeiros e estruturais. Por outro lado, ela monitora cuidadosamente as ações dos competidores, principalmente as líderes de mercado, Nestlé e Danone, e desenvolve suas formulações com base nos produtos dos concorrentes, agregando valor por pequenas diferenciações na embalagem, no sabor e na textura. Essa abordagem estratégica é visível no portfólio atual de produtos e nas tendências de desenvolvimento da empresa.

A trajetória de analisadora da empresa não compromete a importância dada ao compartilhamento de informações e a necessidade de integração das áreas funcionais no desenvolvimento de novos produtos. Para os entrevistados, a integração garantiu organizar, sistematizar e uniformizar as informações advindas dos campos funcionais da organização. 
Conforme Gupta et al. (1986), após o mapeamento da necessidade de integração, seu grau advém de fatores internos da empresa: (1) fatores organizacionais, tais como a estrutura organizacional do processo de desenvolvimento de produtos e o apoio da alta gerência; e (2) fatores individuais.

No que tange os aspectos organizacionais, a empresa adota a forma de equipe multifucional para o desenvolvimento de produtos, Além disso, o apoio da Diretoria é primordial para a concepção da estrutura de integração, bem como no andamento dos projetos em desenvolvimento.

Do ponto de vista dos fatores socioculturais, não houve impacto perante a integração dos atores da empresa. Os conflitos foram considerados tênues e devidamente equacionados durante reuniões ou conversas informais,

O compromisso com a integração dos departamentos ocorre nos níveis estratégico e operacional. No âmbito estratégico, o gerente de produto administra a gestão de novos produtos da sua linha, com o apoio do assessor de marketing e da responsável pela P\&D. Cabe a cada gerente de produto administrar seu portfólio de lançamentos, não havendo, assim, um planejamento centralizado para o desenvolvimento.

No aspecto operacional, a primeira etapa consiste na análise de oportunidades do mercado. As áreas Comercial e de Marketing captam informações de tendências e necessidades de mercado, dos representantes comerciais, dentre outros. O P\&D utiliza também nesta etapa informações provenientes de feiras técnicas, revistas e contatos com fornecedores.

Concluído esta etapa, faz-se a definição do conceito do produto. A elaboração dos conceitos técnicos (textura, sabor e embalagem) e mercadológicos é de responsabilidade do Marketing, P\&D e do Gestor do Produto (Comercial). Na análise da viabilidade técnica-econômica, a produção define o processo de fabricação, a capacidade produtiva e se há ou não necessidade de aquisição de novos equipamentos. Além disso, são estimados o volume de vendas, o custo do produto e o preço, em conjunto com Engenharia, Produção, Comercial, P\&D, Marketing e Financeiro.

O vice-presidente comercial é o responsável pela aprovação do projeto. Após a aprovação, faz-se o desenvolvimento do produto, da embalagem e do processo. O desenvolvimento do produto é dividido em escolha de matéria-prima, desenvolvimento da formulação, testes de protótipos, desenvolvimento da embalagem, envio para o registro, desenvolvimento do processo e testes na linha de produção. A responsável pelo $\mathrm{P} \& \mathrm{D}$ estabelece as matérias-primas que serão utilizadas, verificando se os ingredientes são permitidos pela legislação. Estas informações são enviadas ao setor de compras, que seleciona os potenciais fornecedores, com base nos quesitos custo e qualidade. É verificado se o fornecedor tem a autorização para comercializar o produto. Amostras dos ingredientes são analisadas pelo controle da qualidade para verificar a adequação das matériasprimas, quanto aos aspectos físico-químicos e microbiológicos. 
Aprovada pelo Controle da Qualidade, a matéria-prima é especificada e depois encaminhada ao P\&D para o desenvolvimento da formulação. A responsável pelo P\&D desloca-se para a fábrica de Pará de Minas (MG), onde faz o desenvolvimento. Para comparação com a formulação, são coletadas amostras de concorrentes, que servem como padrão de concorrência. Há reuniões entre P\&D e Produção para a discussão da composição e desenvolvimento da formulação do produto. O controle da qualidade auxilia nos testes físico-quimicos, microbiológicos e os sensoriais. Depois de testes exaustivos de bancada, planta piloto e na linha de bebidas lácteas, chega-se a uma formulação que ainda será validada quanto ao custo e parâmetros de qualidade.

Em paralelo ao desenvolvimento da formulação, é realizado o desenvolvimento das embalagens primária e secundária. Uma agência de publicidade é contratada para elaborar a imagem e o design da embalagem. Concluída esta etapa, a responsável pelo P\&D e o departamento de Compras selecionam os fornecedores de embalagem, com base no quesito de conformidade para especificações técnicas. As informações técnicas e de custo são enviadas ao Marketing que toma a decisão final em conjunto com o gestor de produto.

Após o desenvolvimento da embalagem e da formulação, o supervisor do PCP (Planejamento e Controle da Produção) reúne a documentação técnica necessária para o registro do produto e a envia para o Ministério da Agricultura Pecuária e Abastecimento.

O desenvolvimento de processo de bebidas lácteas considera, caso haja necessidade, o aumento da capacidade produtiva e a definição de parâmetros de controle de processo. A aquisição de novos equipamentos é realizada por Produção e Engenharia. O controle da qualidade auxilia na concepção dos parâmetros, pois retém conhecimento sobre segurança do alimento. Após o encerramento do desenvolvimento do processo, testes em linha são realizados. O P\&D em conjunto com a Produção acompanham exaustivamente os testes. Nesta fase os parâmetros de controle e de processo são validados pelos testes sensoriais, físico-químicos, microbiológicos e de shelf-life,. Há também monitoramento da eficiência da produção.

As estratégias de lançamento de produtos são delineadas pelo Comercial e Marketing. Eles definem os canais de distribuição e as estratégias de promoção serão efetivadas.

Após o lançamento do produto, o acompanhamento é realizado pelo gestor de produto, através da análise de volume de vendas. O Controle de Qualidade monitora o shelf-life durante os testes e após o lançamento do produto.

Os entrevistados ofereceram elementos que permitem concluir, a despeito das diferenças, a ocorrência de um nível satisfatório de integração, embora prescindam da incorporação de mecanismos institucionais que sustente a melhoria e o aprimoramento do processo. 


\subsection{Envolvimento do Fornecedor A no PDP da empresa Alfa}

A empresa Alfa tem a contribuição dos fornecedores de ingredientes no PDP de produtos lácteos, sendo que a extensão do envolvimento de fornecedores de ingredientes ocorre de forma diferenciada. $\mathrm{Na}$ fase do conceito, todos os fornecedores de ingredientes podem apresentar tendências de mercado, novos conceitos e aplicações. Os fornecedores de aroma, estabilizante e preparado de frutas podem interferir no desenvolvimento da formulação do produto na fase de desenvolvimento. Para a fase de produção, os fornecedores de estabilizante fornecem os parâmetros de processo (tempo e temperatura de tratamento térmico).

A decisão sobre fontes de fornecimento de matérias-primas está relacionada com a importância de cada ingrediente na formulação final do produto lácteo. Segundo a responsável pelo $\mathrm{P} \& \mathrm{D}$, os fornecedores de ingredientes que são contatados na fase inicial do PDP de produtos lácteos, como iogurte e bebida láctea, são os de aroma, estabilizante e preparado de frutas. Para o aroma, a empresa Alfa indica os atributos desejados para o fornecedor e este pode desenvolver o componente ou indicar um do portfólio de seus produtos para atendê-los. Já o estabilizante pode ser um blend de ingredientes desenvolvido especificamente para a empresa Alfa ou do portfólio de produtos do fornecedor. E o preparado de frutas é uma mistura de ingredientes (polpa de fruta, aroma, estabilizante, conservante, edulcorante ou açúcar e corante), formulada para a linha de frutas, que atendam às necessidades da empresa. A adoção de preparado de frutas facilita 0 desenvolvimento de novos produtos, pois é só adicioná-lo à base da bebida Láctea ou iogurte (leite, soro, estabilizante e fermento). Um produto novo pode ser proposto, mudando o compounding (combinação de ingredientes), qual seja, pela combinação diferente de alguns ingredientes.

Para análise do envolvimento de fornecedor de ingrediente no PDP da empresa Alfa, optouse por detalhar um projeto de desenvolvimento com o fornecedor A, com o objetivo de enriquecer o levantamento de dados. O projeto foi da bebida láctea achocolatada.

\section{Projeto de bebida Láctea achocolatada}

Neste projeto, o contato inicial foi na fase de desenvolvimento da bebida láctea. $\mathrm{O}$ representante comercial do fornecedor A entrou em contato com o P\&D da empresa Alfa para oferecer seus produtos, e coincidiu que esta empresa estava buscando fornecedores de aroma para reformular a bebida láctea achocolatada. A empresa não especificou o perfil de aroma desejado, só forneceu as necessidades básicas do queria, aroma de chocolate.

O representante comercial entrou em contato com o seu gerente de contas do Fornecedor A para orientar na continuidade do projeto. Foram discutidos a importância do projeto, as especificações do aroma de chocolate e o suporte que deveria ser alocado para este projeto. Como o 
fornecedor A possuía 20 aromas diferentes de chocolate, seu grupo técnico de criação, testou combinações de aromas, chegando a 5 perfis de aroma: chocolate com menta, chocolate com caramelo, chocolate com baunilha, chocolate 1 e chocolate 2 . O tempo para o desenvolvimento desses blends de aromas foi de aproximadamente 20 dias.

Na reunião com a empresa Alfa, o representante comercial apresentou os perfis de chocolate e seus protótipos para degustação para o P\&D e Marketing.

A presença do $\mathrm{P} \& \mathrm{D}$ e do Marketing possibilitou maior eficiência quanto à tomada de decisão e quanto ao fluxo de informação, pois foi possível escolher em conjunto um dos perfis apresentados pelo representante, chocolate com malte.

O tempo do desenvolvimento da bebida Láctea achocolatada, perfil chocolate com menta, da empresa Alfa foi de quase 1 ano, sendo que o projeto entre fornecedor A e empresa Alfa durou 5 meses.

O P\&D da empresa Alfa foi responsável pela coordenação desse projeto junto ao fornecedor A. As áreas funcionais da empresa Alfa que entraram em contato com o fornecedor A via representante comercial durante o projeto da bebida láctea perfil chocolate com menta foi o P\&D e o Marketing, este último foi na apresentação dos perfis de chocolate. O departamento de compras da empresa Alfa entrou só no final do desenvolvimento da bebida para a negociação de preços e de volume de compra do ingrediente.

Sob este prisma, a integração das percepções entre P\&D e Marketing nas fases iniciais do desenvolvimento do projeto permitiu um maior envolvimento e troca de informações com o fornecedor para a escolha da melhor opção de aroma. Atende-se aos preceitos de Hillerbrand e Biemans (2004), ao apontar que a integração interfuncional é um pré-requisito para um relacionamento efetivo interorganizacional, servindo como mecanismo para coordenar a cooperação externa.

No entanto, a percepção positiva das integrações intra e interorganizacionais, porém, conflita com a limitação da mensuração da eficiência do processo integrativo. A empresa Alfa não mensura as ações de cada departamento e dos fornecedores com relação ao desempenho do produto. No entendimento dos entrevistados, os indicadores do produto norteiam os projetos desenvolvidos, mas não há uma reflexão sobre a contribuição d para o sucesso ou fracasso do projeto.

\subsection{Percepção dos entrevistados e informações dos documentos}

As percepções dos entrevistados quanto ao processo de desenvolvimento de produtos foram sintetizadas e esquematizadas conforme consta no Quadro 4. 
Quadro 4 - Percepções dos Entrevistados

\begin{tabular}{|c|c|c|}
\hline & Tópicos & Empresa Alfa \\
\hline \multicolumn{2}{|c|}{ Ambiente Externo } & $\begin{array}{l}\text { Alta influencia na gestão de } \\
\text { desenvolvimento de produtos }\end{array}$ \\
\hline \multicolumn{2}{|c|}{ Estratégia organizacional } & Analisadora \\
\hline \multicolumn{2}{|c|}{$\begin{array}{c}\text { Necessidade percebida para } \\
\text { integração }\end{array}$} & Alta \\
\hline \multirow{3}{*}{$\begin{array}{l}\text { Fatores } \\
\text { internos }\end{array}$} & \multirow{2}{*}{ Fatores organizacionais } & Estrutura matricial \\
\hline & & Apoio da alta direção \\
\hline & Fatores individuais & Conflitos tênues \\
\hline \multirow{2}{*}{\multicolumn{2}{|c|}{ Integração entre os departamentos }} & Nível estratégico \\
\hline & & Nível operacional \\
\hline \multicolumn{2}{|c|}{ Integração com os fornecedores } & $\begin{array}{l}\text { Forma diferenciada - depende } \\
\text { do projeto }\end{array}$ \\
\hline \multicolumn{2}{|c|}{$\begin{array}{c}\text { Diferença a integração desejada e a } \\
\text { real }\end{array}$} & Baixa \\
\hline \multicolumn{2}{|c|}{$\begin{array}{c}\text { Relação entre sucesso do projeto com } \\
\text { integração }\end{array}$} & Não é refletida na Empresa \\
\hline
\end{tabular}

\section{Considerações Finais}

No intuito de elucidar, ainda que parcialmente, o complexo fenômeno da cooperação intra e interorganizacional no desenvolvimento de produto, estudou-se a atuação das áreas funcionais de uma empresa de laticínios no PDP e a participação de um fornecedor de ingrediente em um projeto com esta empresa.

O sucesso no processo de desenvolvimento de novos produtos depende da cooperação entre áreas funcionais para que todas as atividades sejam desempenhadas da melhor forma. Nesta pesquisa, o funcionamento desse ciclo cooperativo otimizou o processo e favoreceu a sinergia entre as partes. Kahn (2001) reconhece a importância da integração entre os diversos setores no processo de desenvolvimento de produtos, por favorecer o aumento da flexibilidade frente às mudanças inesperadas durante o desenvolvimento, como também a visão do projeto como um todo e não fragmentado em partes.

Além disso, a relação industrial entre fornecedores de ingrediente e a empresa de laticínios, facilita o compartilhamento de ações no desenvolvimento de novos produtos, concordando com Clark e Fujimoto (1991), Clark e Wheelwright (1993) e Rozenfeld et al. (2006), que salientam a importância do envolvimento de fontes externas para otimizar o processo.

A atuação dos fornecedores de ingredientes ocorre de forma distinta, dependendo do tamanho, do escopo e da complexidade do projeto, conforme Amaral (1997). No caso do projeto de bebida láctea achocolatada, o envolvimento do fornecedor A no desenvolvimento do produto da 
empresa Alfa se deu, principalmente na fase do desenvolvimento e o tipo de projeto é caracterizado como black box, sendo o fornecedor o responsável pelo projeto de desenvolvimento do ingrediente.

Nesta pesquisa, observou-se a influência da integração entre os departamentos da empresa Alfa na relação com o fornecedor. Permitiu-se um fluxo maior de informações ao unir diferentes visões para a escolha do melhor aroma.

A percepção positiva da integração confronta-se com a limitação da mensuração da eficiência do processo integrativo. A organização não mensura as ações de cada departamento e dos fornecedores relacionando-as com o desempenho do produto. No entendimento dos entrevistados os indicadores do produto norteiam os projetos desenvolvidos, mas não ocorre uma reflexão sobre a contribuição de cada departamento para o sucesso ou fracasso do projeto. A integração promove a disseminação das informações, evitando retrabalho de projeto e erros de lançamento, mas sem oferecer elementos para tratamento como indicadores de desempenho da equipe.

\begin{abstract}
New products development is covered of wide complexity, that leads to dependencies among different functional areas, requiring inputs and cooperation from different departments, such as Marketing, Production, Research and Development and Quality Control. Besides, to acomplish sucess during the product development, the company needs supplier's technology support to incorporate in its process. Therefore, this study analyzes intra and inter-organizational integration across the development of dairy products. The study used an exploratory research with case study method in a dairy company and one of its ingredients' suppliers. The results indicates that even the company develop products that already exists in the market, integration is observed among the functional areas and with the suppliers across the product development process. However, there isn't a reflection on the each functional department and supplier's roles for the project success or failure. It was also verified that the extension of the supplier involvement in the product development is related to the difference in the technical competence between the companycustomer and the supplier
\end{abstract}

Key-words: product development, integration, new products

\title{
Referências
}

AMARAL, D. C. Colaboração Cliente-Fornecedor no Desenvolvimento de Produto: Integração, Escopo e Qualidade do Projeto do Produto: estudos de casos na indústria automobilística Brasileira. São Carlos, 1997.

Dissertação (Mestre em Engenharia de Produção) - Departamento de Engenharia de Produção, Universidade Federal de São Carlos.

AMARAL, D.C.; TOLEDO, J.C. Colaboração Cliente-Fornecedor no Processo de Desenvolvimento de Produto: Estudo de Casos na Indústria de Autopeças. Gestão \& Produção. v. 7, p. 56-72, abr. 2000.

CASTRO, M. C. D; NEVES, C. S. dos. Análise da evolução recente e perspectivas da indústria laticinista no Brasil. In: GOMES, A. T; LEITE, J. L. B; CARNEIRO, A. V. (Ed) O agronegócio do leite no Brasil. Juiz de Fora: Embrapa Gado de Leite, 2001.

CHENG, L.C. Caracterização da Gestão de desenvolvimento do produto: delineando o seu contorno e dimensões básicas. In: Congresso Brasileiro de Gestão de Desenvolvimento de Produto, II, 2000, São Carlos. Anais ... São Carlos: UFSCAR, 2000. p. 1-9. 
CLARK, K., FUJIMOTO, T. Product Development Performance- Strategy, Organization, and Management in the World Auto Industry. Boston: Havard Bussiness Scool Press, 1991.

CLARK, K., WHEELright, S. C. Managing New Product and Process Development: Test and Cases. New York: Fee Press, 1993.

FLEURY, A.; FLEURY, M. T. Estratégias competitivas e competências Essenciais: perspectivas para a internacionalização da indústria no Brasil. Gestão \& Produção, v. 10, n. 2, pp. 129-144, 2003.

FULLER, G. W. New Food Development - from Concepts to Marketplace. United States: CRC Press,1994.

GRIFFIN, A. PDMA Research on New Product Development Practices: Updating Trends and Benchmarking Best Practices . Journal of Product Innovation Management, v. 14, p. 429-458, 1997.

cross ${ }^{\text {ref }}$

GRIFFIN, A. HAUSER, J. R. Integrating R\&D and Marketing: A Review and Analysis of the Literature. Journal of Product Innovation Management. v. 13; p. 191-215. 1996.

cross ref

GUPTA, A. K; RAJ, S. P; WILEMON, D. A model for Studying R\&D-Marketing Interface in the Product Innovation Process. Journal of Marketing. v. 50; p. 7-17. 1986.

cross ${ }^{\text {ref }}$

HANDFIELD, R. B., RAGATZ, G. L., PETERSEN, K. J., MONCZKA, R. M. Involving suppliers in new product development. California Management Review, v. 42, n. 1, p. 59-82, 1999.

HILLEBRAND, B.; BIEMANS, W.G. Links between Internal and External Cooperation in Product Development: an exploratory study. Journal of Product Innovation Management, v. 21, n. 2, p. 110-122, 2004.

cross ${ }^{\text {ref }}$

HOOD, L. L., LUNDY, R. J., JOHNSON, D. C. New product development: north american ingredient supplier's role. British Food Journal, v. 97, n. 3, p. 12-17, 1995.

cross ref

KAHN, K. B. Market orientation, interdepartmental integration, and product development performance. Journal of Product Innovation Management. v. 18; p.314-323. 2001.

cross ref

MARTINELLI Jr, O. A globalização e a indústria alimentar: um estudo a partir das grandes empresas. Marília: UNESP-Publicações; São Paulo: FAPESP. 198 p. 1999.

MILES, R. E; SNOW, C. C. Organizational strategy, structure, and process. New York ; SãO Paulo: McGraw-Hill Book, c1978. 274p.

OLSON, E. M; WALKER Jr, O. C; RUEKERT, R. W; BONNER, J. M. Patterns of cooperation during new product development among marketing, operations and R\&D: Implications for project performance. Journal of Product Innovation Management. v. 18; p. 258-271. 2001.

crossef

ONOYAMA, M.M. Participação do fornecedor de ingredientes no desenvolvimento de produtos: estudo de casos em processadoras de bebidas. São Carlos, 2006. Dissertação (Mestre em Engenharia de Produção) - Departamento de Engenharia de Produção, Universidade Federal de São Carlos.

RAGATZ, G. L., HANDFIELD, R. B., SCANNEL, T. V. Sucess Factors for Integrating Suppliers into New Product Development. Journal of Product Innovation Management, v. 14, n.3, p. 190-202. 1997.

cross ref

ROZENFELD, H. et al. Gestão de Desenvolvimento de Produtos: uma referência para a melhoria do processo. São Paulo: Saraiva. 2006. 
SOBRAL, M. C. Gestão do Desenvolvimento de Produtos: um contraste entre desenvolvimento conjunto e desenvolvimento interno. São Paulo, 2003. Dissertação (Mestre em Administração) - FEA, Universidade de São Paulo.

SONG, X. M; THIEME, R. J; XIE, J. The Impact of Cross-Funcional Joint Involvement Across Product Development Stages: An Exploratory Study. Journal of Product Innovation Management. v. 15; p. 289-303. 1998.

cross ${ }^{\text {ref }}$

TAKEISHI, A. Brigding Inter- and Intrafirm Boundaries: Managment of Supplier Involvement in Automobile Product Development. Strategic Management Journal, v. 22, n. 5, p. 403-433. 2001.

cross ${ }^{\text {ref }}$

TOLEDO, J.C. et al. Gestão do Processo de Desenvolvimento de Produto na Indústria de Alimentos: análise, propostas para melhoria da capacitação e modelo de referência. In: BATALHA, M.O. Gestão do Agronegócio: textos selecionados. São Carlos: EdUFSCar, 2005.

TOLEDO, J.C.; SILVA, S.L.; MENDES, G.H.S.; JUGEND, D.; PAULA, S.M. Gestão do Processo de Desenvolvimento de Produto em Empresas de Base Tecnológica de pequeno e médio porte do Estado de São Paulo: diagnóstico e proposição de modelo de referência. Relatório Pesquisa n. 2 (Parcial). Processo Fapesp n. 03/10863-4, 2006.

VIANNA, I. O. de A. Metodologia do Trabalho Científico: um enfoque didático da produção científica. São Paulo: E. P. U., 2001.

WYNSTRA, F.; TEN PIERICK, E. Managing supplier involvement in new product development: a portfolio approach. Journal of Purchasing \& Supply Management. v. 6, p. 49-57. 2000.

cross ${ }^{\text {ref }}$

YIN, R.K. Estudo de Caso: planejamento e métodos. Porto Alegre: Bookman. 2a ed. 2001.

\section{Dados dos autores:}

Nome completo: Silvia Satiko Onoyama

Filiação institucional: EMBRAPA - Hortaliças

Departamento: Pesquisa \& Desenvolvimento \& Inovação

Função ou cargo ocupado: Analista

Endereço completo para correspondência (bairro, cidade, estado, país e CEP): Rodovia

Brasília/Anápolis BR 060 Km 09, Brasília - DF , Brasil, Caixa Postal 218 CEP 70359-970

Telefones para contato: $61-3385-9000$

e-mail:silonoyama@yahoo.com

Nome completo: Marcia Mitiko Onoyama

Filiação institucional: Universidade Federal de São Carlos

Departamento: Engenharia de Produção

Função ou cargo ocupado: Doutoranda

Endereço completo para correspondência (bairro, cidade, estado, país e CEP): Alameda dos Crisantemos 60, bloco B apt 22. São Carlos, SP, Brasil, 13566-550 
Telefones para contato: 16-3361-3405

e-mail:onoyama@dep.ufscar.br

Nome completo: José Edson Lara

Filiação institucional: Universidade Federal de Minas Gerais

Departamento: Faculdade de Ciências Econômicas, Departamento de Ciências Administrativas

Função ou cargo ocupado: Professor Associado

Endereço completo para correspondência (bairro, cidade, estado, país e CEP): Rua Curitiba, 832 -

Sala 1207, Centro, - Belo Horizonte, MG - Brasil, cep 30170120

Telefones para contato: 31 - 32799046

e-mail:jedson@face.ufmg.br

Nome completo: Maria Rita Pontes Assumpção

Filiação institucional: SENAI Cimatec

Departamento: Núcleo Gestão e Logística

Função ou cargo ocupado: Coordenadora

Endereço completo para correspondência (bairro, cidade, estado, país e CEP): Avenida Orlando Gomes 1845 SALVADOR - BA, Brasil, 41650-010

Telefones para contato: 71-3462-8434

e-mail: mariarpa@,cimatec.fieb.org.br

Nome completo: José Carlos de Toledo

Filiação institucional: Universidade Federal de São Carlos

Departamento: Engenharia de Produção

Função ou cargo ocupado: Professor Titular

Endereço completo para correspondência (bairro, cidade, estado, país e CEP): Rod. Washington Luís - Km 235. São Carlos, São Paulo - Brasil. CEP: 13565-905

Telefones para contato: 16 -3351-8236. Ramal 9215

e-mail:toledo@dep.ufscar.br

Recebido para publicação em: 01/02/2008

Aceito para publicação em: 25/02/2008 